\title{
Sade, Contes étranges
}

\section{Vittorio Fortunati}

\section{(2) OpenEdition}

\section{Journals}

\section{Edizione digitale}

URL: http://journals.openedition.org/studifrancesi/469

DOI: 10.4000/studifrancesi.469

ISSN: 2427-5856

\section{Editore}

Rosenberg \& Sellier

\section{Edizione cartacea}

Data di pubblicazione: 1 aprile 2015

Paginazione: 153

ISSN: 0039-2944

\section{Notizia bibliografica digitale}

Vittorio Fortunati, «Sade, Contes étranges », Studi Francesi [Online], 175 (LIX |I) | 2015, online dal 01 avril 2015, consultato il 18 septembre 2020. URL : http://journals.openedition.org/studifrancesi/469 ; DOI : https://doi.org/10.4000/studifrancesi.469

\section{Questo documento è stato generato automaticamente il 18 settembre 2020.}

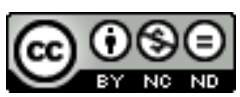

Studi Francesi è distribuita con Licenza Creative Commons Attribuzione - Non commerciale - Non opere derivate 4.0 Internazionale. 


\title{
Sade, Contes étranges
}

\author{
Vittorio Fortunati
}

\section{NOTIZIA}

SADE, Contes étranges, édition de Michel DELON, Paris, Gallimard, 2014, pp. 384.

1 Il marchese de Sade diede, come è noto, alle stampe nel 1800 un volume intitolato Les Crimes de l'amour, che conteneva una parte dei suoi racconti, mentre altri vennero pubblicati postumi. Questi ultimi (insieme con alcuni inediti) appaiono ora, grazie a Michel Delon, in una nuova edizione basata sui manoscritti autografi. La raccolta comprende una trentina di testi, molto diversi quanto a lunghezza e contenuto: gli aneddoti si alternano infatti a narrazioni più articolate, le novelle galanti o boccaccesche a racconti in cui l'irriverenza supera i confini del blasfemo. L'aggettivo étranges del titolo, scelto dal curatore, fa esplicito riferimento a una caratteristica comune a quasi tutte le storie: la presenza di situazioni inattese, insolite, bizzarre, comunque in contrasto coi pregiudizi, coi valori condivisi, con lo stesso senso comune. Come sottolinea M. Delon nella prefazione, questi brevi scritti di Sade «racontent des discordances: discordances du désir avec l'ordre social, de la réalité vécue avec les théories» (p. 11). Tra le istituzioni prese di mira dalla feroce satira del marchese, un posto di riguardo (per così dire) spetta, accanto al matrimonio, alla giustizia: per esempio, ne Le Président mystifié, che non a caso è il più lungo dei Contes (pp. 150-232), i magistrati sono descritti come individui ipocriti, crudeli, inetti, profittatori, in ultima analisi come una categoria parassitaria, oltre che pericolosa per la società. Non va dimenticato, naturalmente, che questi racconti furono composti, in gran parte, durante i numerosi periodi di prigionia del loro autore.

2 Questa edizione è corredata da un corposo apparato di note (pp. 322-381), che, oltre alle varianti e alle necessarie delucidazioni, forniscono la fonte di buona parte dei testi. Il modello più imitato (con passi quasi interamente copiati) sono le Lettres historiques et galantes (1707) di Madame Du Noyer. Quest'ultima era una scrittrice protestante di Nîmes: anche per questo (oltre che per le origini del marchese) molte delle vicende 
narrate si svolgono nella Francia meridionale. Gli specialisti sono concordi nell'affermare che i testi brevi rappresentano una componente importante dell'opera narrativa di Sade, non solo perché alcuni di essi costituiscono il primo abbozzo dei più celebri romanzi, ma soprattutto per la presenza delle principali tematiche e dei più tipici tratti stilistici dello scrittore. La pubblicazione dei Contes étranges in una collana accessibile come «Folio classique» sarà senz'altro un'occasione perché essi siano conosciuti e apprezzati anche da un pubblico di lettori non specialisti. 